Nig. J. Biotech. Vol. 37(2): 95-102 (Dec. 2020)

ISSN: 01891731

Available online at

http://www.ajol.info/index.php/njb/index

and www.biotechsocietynigeria.org

DOI: https://dx.doi.org/10.4314/njb.v37i2.9

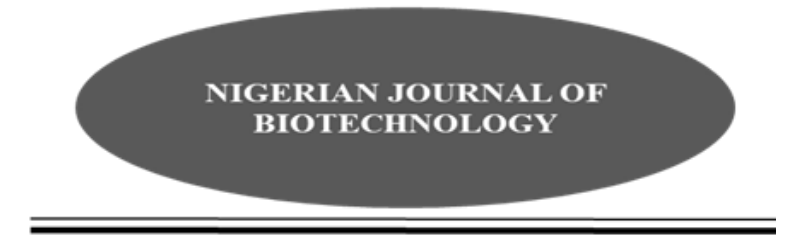

\title{
Detection of integron genes in the plasmid DNA of multidrug resistant Pseudomonas aeruginosa isolated from surgical wounds of some patients in Benin City, Nigeria
}

\author{
EREMWANARUE, A. $0^{1,2}{ }^{\prime}$, SHITTU, H. $0^{1}{ }^{1}$, IGIEHON, ${ }^{1}{ }^{1}$, and OIJAGBE, E. R ${ }^{1}$ \\ ${ }^{1}$ Department of Plant Biology and Biotechnology, University of Benin, PMB, 1090, Ugbowo, Benin City, \\ Nigeria \\ ¿2ahor Research Laboratories and Diagnostics Centre, 121, Old Benin-Agbor Road, Benin City, Nigeria
}

\begin{abstract}
Pseudomonas aeruginosa is an opportunistic pathogen with the capability to cause serious surgical wound infections and remains a major healthcare problem. Plasmid is an extra chromosomal material in bacterial cells and confers resistance to the cell against many antibiotics. Genetic elements such as integron are implicated in conferring multidrug resistance (MDR) to $P$. aeruginosa . This study aims at investigating the occurrence of integron genes (int1, int2, int3) in the plasmid DNA and their ability to cause MDR in $P$. aeruginosa . In total, 284 different wound swabs were collected, $P$. aeruginosa isolated and screened using standard laboratory methods. Antibiotics susceptibility tests were carried out using Kirby-Bauer disk diffusion method. Polymerase chain reaction (PCR) was also carried out using $\quad$ P. aeruginosa plasmid DNA as a template to detect the presence/absence of the integron genes using different pairs of specific primers. The results reveal that $34(54.8 \%)$ of the microbes isolated were $P$. aeruginosa Most of the isolates showed notable resistance to antibiotics, most notably against Ceftazidime, Augmentin, Cefixime and Gentamicin . Eleven isolates harbors the plasmid DNA . PCR amplification showed that $6(54.5 \%)$ of the $P$. aeruginosa isolates harbor integron class 1 genes, non harbors the integron class 2 genes while $3(27.3 \%)$ possess the integron class 3 genes. The isolates with these genes were highly resistant to most of the antibiotics used. int1 gene was prevalent then int3.
\end{abstract}

Keywords: Antimicrobial, Wound infection, Integron, Polymerase chain reaction, Plasmid DNA

*Corresponding author: Aibuedefe Osagie Eremwanarue, E-mail: eremwanarueaibuedefe@yahoo.com, Telephone: +2348037945407

Introduction

Pseudomonas aeruginosa is an opportunistic infection causing bacteria with the likelihood to cause severe healthcare-related infections particularly in immune-compromised post surgical wound patients (Strateva and Yordanov, 2009). Generally speaking, surgical wounds via suppression of the body defense system present a suitable site for microorganism multiplication. Therefore, $P$. aeruginosa infection in surgical wound patients is frequent and is seen as one of the leading serious life- threatening conditions in surgical operation units (Church et al., 2006). Moreover, due to the resistance of these 
microorganisms to a huge assortment of routinely used antibiotics in recent years, dealing with infections caused by them has been wearisome and has resulted in enhanced mortality (Fair and Tor, 2014). The acquired and intrinsic (low outer membrane Permeability, over expression of efflux pump) antibiotic resistance ability of $P$. aeruginosa makes it difficult for the treatment of $P$. aeruginosa surgical wound infections (Breidenstein et al., 2011).

Bacteria plasmid DNA are second chromosomal material of limited size, frequently firmly inherited in a bacterial cell and potentially able to transfer between strains, species or genera (Alan, et al., 2001). One of the major purposes of plasmid is to transfer genes that confer resistance to drugs used in the treatment of infectious diseases (Alan, et al., 2001).

Integrons are mobile genetic elements which can be found in plasmids, transposons and chromosomal DNA. These are sometimes accountable for the progress in microbial resistance among Gram-negative bacteria pathogens (Fluit and Schmitz, 2004; Gillings, 2014). Integrons are composed of three vital core parts which include the intI gene which codes for integrase (IntI) necessary for sitespecific recombination; attI, the bordering recombination site that is identified by the integrase; and integron related promoter (Pc), which is required for transcription and expression of gene cassettes within the integron. Gene cassettes are genetic components that encode antibiotic resistance, and incorporate a specific site recombination known by integrase which is referred to as attC (Domingues et al., 2012). Due to the type of genes encoded in integrases, integron has been separated into five groups (Cambray et al., 2010; Deng et al., 2015). Integron class 1 type is the most widely distributed integrase gene in drug resistant bacteria isolates (Deng et al., 2015). There is dearth of documented studies due to the significance of plasmid DNA and integron in the wide spread of antibiotic resistance . This study is aimed at investigating the incidence of class 1, 2 and 3 integrons in plasmid DNA of multidrug resistant $P$. aeruginosa isolated from post surgical wound infection in Benin City, Nigeria.

\section{Materials and Methods}

\section{Sample collection}

A total of 284 random swab sampling of post operative surgical wounds were collected from both outpatients and inpatients in the University of Benin Teaching Hospital and Central Hospital, Benin City.

\section{Ethical clearance}

Approval was obtained from the University of Benin Teaching Hospital and Central Hospital, ethical committees and all patients gave their support after being educated of the objectives of the study.

\section{Bacteriological procedures/identification of} isolates

All wound samples were inoculated as described by Eremwanarue and Shittu (2018). Phenotypic methods were used the in identification of all isolates (Cheesbrough, 2000).

\section{Antibiotic susceptibility testing}

The Kirby-Bauer disk diffusion method was employed in generating multiple drug resistant isolates with routinely used antimicrobial agents (CLSI, 2011). The antibiotics used include Nitrofurantion (NIT 300 $\mu$ ), Augmentin (AUG, $30 \mu \mathrm{g})$, Gentamycin (GEN 30 $\mathrm{g}$ ), Ciprofloxacin

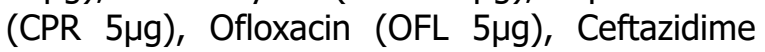

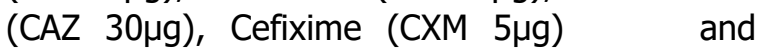

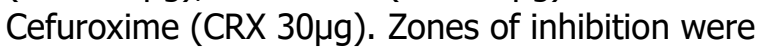
interpreted using the Performance Standards for antimicrobial disk susceptibility tests (CLSI, 2011).

\section{Bacterial genomic DNA extraction}

The multidrug resistant Pseudomonas aeruginosa were sub-cultured overnight in LuriaBertani broth (Merck, Germany) and plasmid DNA was extracted using Zymopure plasmid DNA extraction kits (Irvine, CA, USA), following the manufacturer's instructions.

Detection of integron genes in plasmid DNA of Pseudomonas aeruginosa

The amplification of plasmid DNA containing the integron genes in Pseudomonas aeruginosa was carried out using the forward and reverse 
primers for integron class I, 2 and 3 (Int1-FGCCACTGCGCCGTTACCACC; Int1-RGGCCGAGCAGATCCTGCACG, IntI2-FCACGGATATGCGACAAAAAGGT; IntI2-RGTAGCAAACGAGTGACGAAATG, IntI3-F AGTGGGTGGCGAATGAGTG; IntI3-RTGTTCTTGTATCGGCAGGTG) [Sunde, 2005; Mohammadalipour et al, 2017] separately in a ABI9700 thermal cycler PCR machine at Lahor Research Laboratories, Benin City, Nigeria. Quick load PCR Master Mix 2x (New England Biolab, USA) was used in line with the manufacturer's instructions. The PCR was performed in $25 \mu \mathrm{l}$ reaction volume and PCR conditions as described by Eremwanarue and Shittu (2018), with annealing temperature at $54^{\circ} \mathrm{C}$ for 30 seconds. The amplified PCR products ( $10 \mu \mathrm{l}$ each) were separated on a $1 \%$ agarose gel stained with ethidium bromide in TBE buffer and ran at 90 Volts for 60 minutes. The gel was viewed using a gel documentation system (Wealth Dolphin Doc) and snapped.

Results and

\section{Discussion}

The broad spread of antibiotic resistant genes among bacteria as well as $P$. aeruginosa strains is worrisome in the cure for post surgical wound infections. A total of two hundred and eighty four (284) post operative surgical wound swabs specimens from in and out patients were analyzed. Of all the patients studied,

99

(35\%) of them had wound infections. is lower than $39.9 \%$ previously reported (Mohammed et al., 2006; Oni et al., 2013) but higher than $9.6 \%$ reported by Dellinger et al. (2005). Nevertheless, the prevalence rate observed in this study is not in any way different from the rate suggested by the World Health Organization (WHO, 2011). The etiologic agents isolated from the surgical wounds showed that $P$. aeruginosa (62.6\%) was the major cause of the wound infection. This is in conformity with the research work of Sulochana et al. (2014) who, as well, reported that $P$. aeruginosa was the main cause of surgical wound infections.

The sixty two $P$. aeruginosa isolated from the surgical wounds were screened to identify antibiotic resistant strains and the presence of int1, int2 and int3 genes. Thirty four (54.8\%) isolates showed multiple drug resistance. On the basis of the antibiotics susceptibility results observed, most isolates showed high resistance to Ceftazidime, Augmentin, Cefixime and gentamicin (54.8\%). Figure 1 showed the antibiotic resistance result of the strains of $P$. aeruginosa using eight commonly used drugs. In this study, the antibiotic sensitivity testing revealed that most of our isolates showed resistance $(>50.0 \%)$ to the commonly used antibiotics. Ehiaghe et al. (2016), reported high resistance of some bacterial isolates from clinical samples to first, second and third generation antibiotics. Yah et al., (2010) reported that bacteria isolated from surgical wounds are mostly resistant to Ceftazidime and Augmentin, which may be due to occurrence of Cephalosporinase and Penicillinase (Fontana et al., 2000).

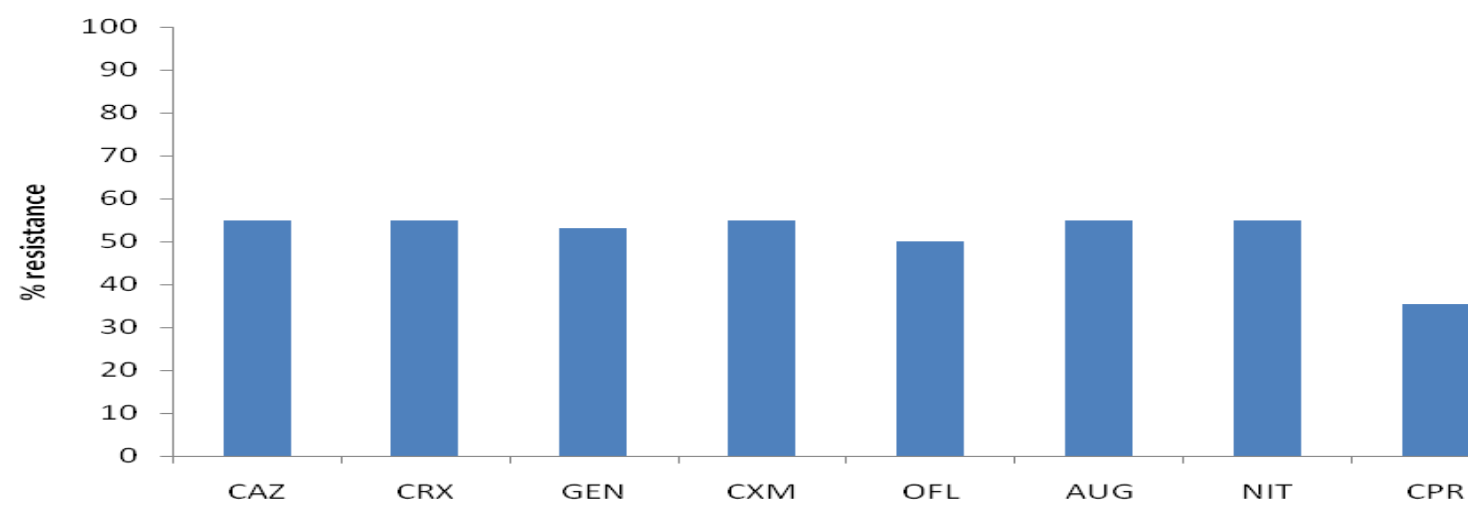

Fig 1: Antimicrobial resistance pattern of Routine Antibiotics $P$. aeruginosa isolates. CAZ: Ceftazidime, CRX: Cefuroxime, GEN: Gentamicin, CXM: Cefixime, OFL: Ofloxacin, AUG: Augmentin, NIT: Nitrofuration, CPR: Ciprofloxacin 
There are numerous antibiotics resistant gene cassettes within bacteria integrons, which can as well be situated on mobile genetic elements such as plasmids and transposons (Gu et al., 2007). Plasmid DNA profiling of the thirty four multidrug resistant (MDR) Pseudomonas aeruginosa strains showed that eleven (32.4\%) isolates were found to harbor plasmid genes as shown in plates 1 and 2. Plasmids analysis revealed that eleven MDR $P$. aeruginosa (P20, P31, P33, P60, P78, P80, P32, $\mathrm{P} 38, \mathrm{P} 75, \mathrm{P} 17$ and $\mathrm{P} 23$ ) had detectable plasmid DNA genes which represents $32.4 \%$ of the MDR strains analyzed. Plasmid DNA profiling reveals that the total microbial plasmids are fragmented by electrophoresis. This technique is used to evaluate the wide spread of antibiotics plasmid DNA resistance (Clowers, 2004).

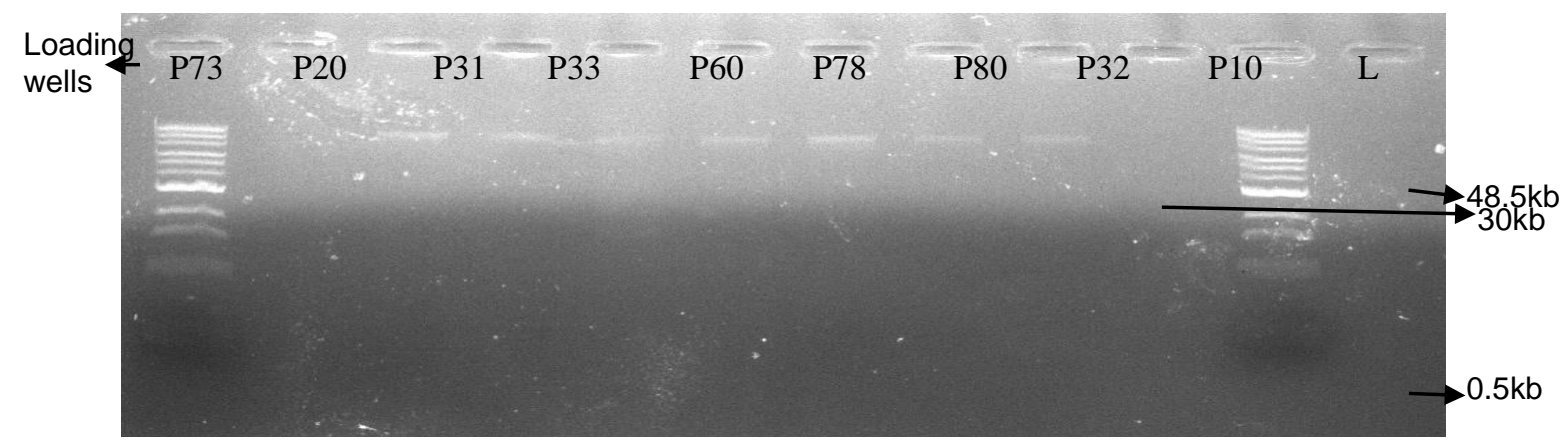

Plate 1: Plasmid profile of cured multiple drug resistant Pseudomonas aeruginosa strains. $L$ is $0.5 \mathrm{~kb}-48.5 \mathrm{~kb}$ DNA ladder, isolates P20, P31, P33, P60, P78, P80 and P32 harbors plasmid genes with bands at 30kb, P73 and 10 did not harbor plasmid genes.

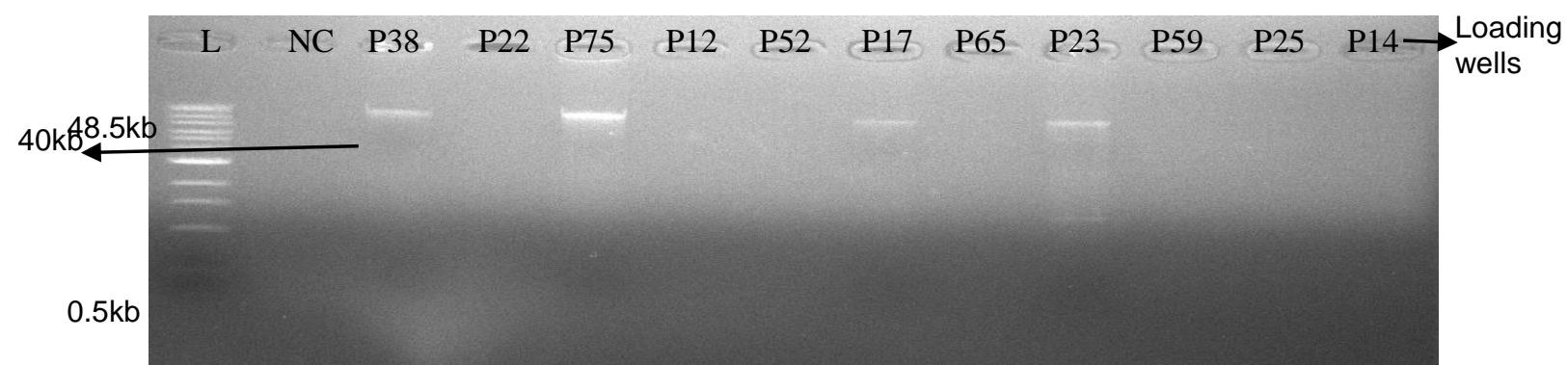

Plate 2: Plasmid profile of cured multiple drug resistant Pseudomonas aeruginosa strains. $L$ is $0.5 \mathrm{~kb}-48.5 \mathrm{~kb}$ DNA ladder, isolates P38, P75, P17 and P23 harbors plasmid genes with bands at 40kb, P22, P12, P52, P65, P59, P25 and 14 did not harbor plasmid genes. NC: is a negative control.

In the present study, PCR amplification was carried out to detect the three classes (int1, int2, int3) of integron genes in the plasmid DNA isolated from the MDR $P$. aeruginosa. The results revealed that $6(54.5 \%)$ of the plasmid- positive
MDR $P$. aeruginosa strains harbor integrase class 1 genes ( Plate 3 ), non (100\%) of the plasmid- positive isolates was found to contain class 2 integrase genes ( Plate 4) and only 3 $(27.3 \%)$ of them carried int3 gene ( Plate 5). 


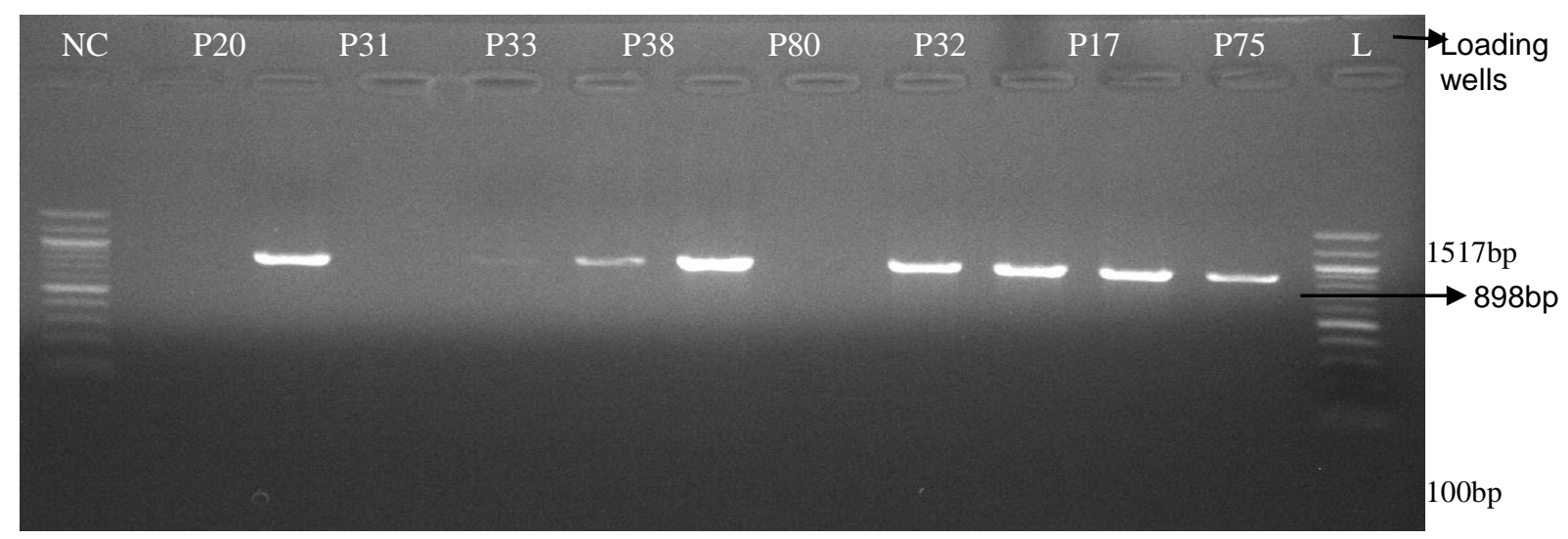

Plate 3. PCR detection of integrase class 1 genes in plasmid DNA of Pseudomonas aeruginosa strains shows that isolates P20, P31, P33, P80, P32, P17 and P75 harbors int1 genes with bands at 898bp while isolates P38 and others were didn't have int1 genes. NC: is a negative control.

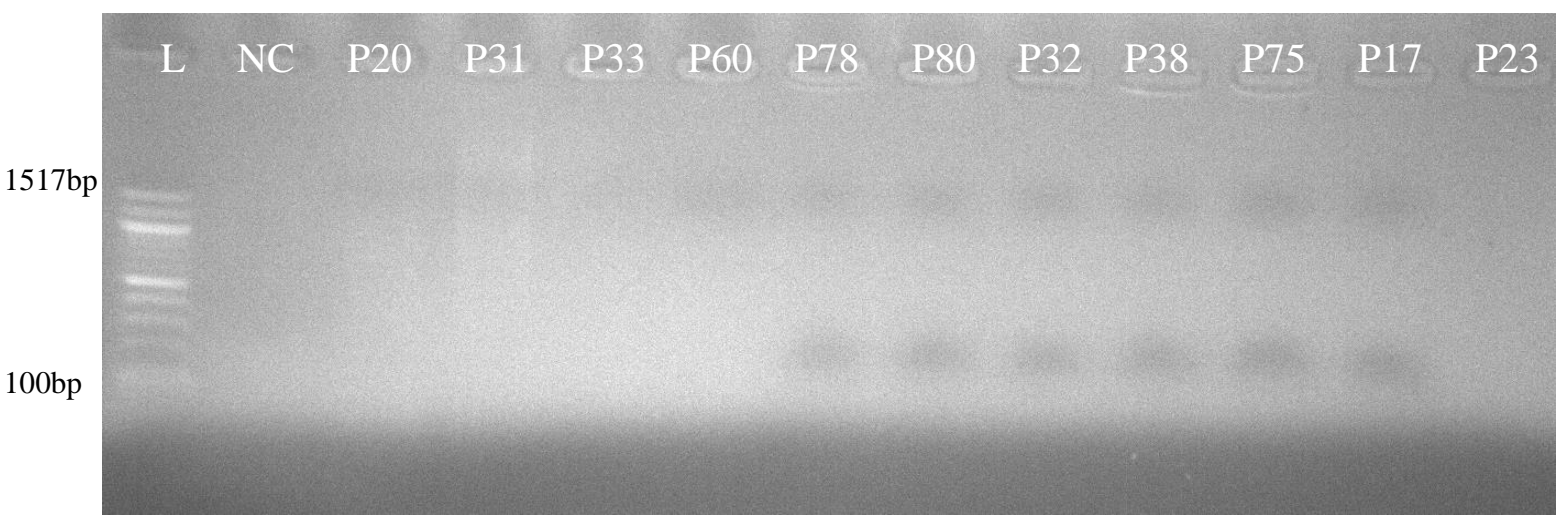

Plate 4. PCR detection of integrase class 2 genes in plasmid DNA of Pseudomonas aeruginosa strains shows that all isolates P20, P31, P33, P60, P78, P80, P32, P38, P75, P17 and P23 did not harbors int2 genes. NC: is a negative control.

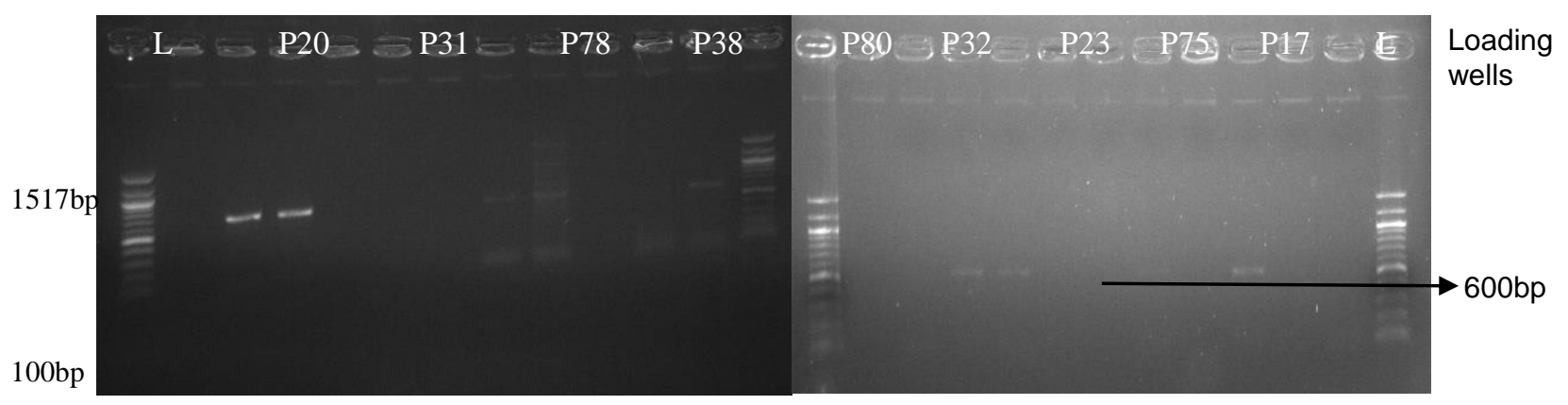

Plate 5. PCR detection of integrase class 2 genes in plasmid DNA of Pseudomonas aeruginosa strains shows that isolates P31, P78, and P23 harbors int3 genes with bands at 600bp while isolates P20, P38, P80, P32, P75 and P17 did not harbors int3 genes. 
To the best of our knowledge, there is no documented information on the presence of integron genes in the plasmid DNA of MDR $P$. aeruginosa. The frequency of int 1 gene in the genomic DNA of clinical isolates of $P$. aeruginosa has been acknowledged in numerous similar research work from around the world, ranging from 43\% to 56.3\% (Nikokar et al., 2013; Sun et al., 2014). In this study, none of the MDR $P$. aeruginosa harbored int2 gene. This was in concordance to the investigation conducted by Khosravi et al. (2017), who also reported zero occurrence of int2 gene in the genomic DNA of all the $P$. aeruginosa they screened , although other researchers reported the occurrence of class 2 integron gene in the genomic DNA of the bacteria to be $19.5 \%$ and $2.7 \%$ (Xu et al 2009; Moazami and Eftekhar, 2015). Integron class 3 genes were detected in the plasmid DNA of three (27.3\%) of the multidrug resistant $P$. aeruginosa strains. Zero occurrence of int/3 gene in the genomic DNA of the bacteria was reported by Mohadeseh Zarei et al. (2018). The presence and proliferation of class 3 integrons genes could carry an assortment of resistant gene cassettes which can make the plasmid DNA- positive bacterial multiple drug resistance more worrisome worldwide (Shibata et al., 2003).

All the plasmid- positive isolates in our study were multidrug resistant isolates. Integrons are eminently related to multidrug resistance, particularly integron class 1 which was broadly disseminated in $P$. aeruginosa. We found high antibiotics resistance among the $P$. aeruginosa isolates with plasmid DNA that harbors integron genes, especially those with int1. As stated formally , researchers had recognized that multidrug resistance is strongly connected with the presence of integrons, and a greater part of our MDR isolates comprise int1 gene. However, the presence of integron genes in the plasmid DNA of some $P$. aeruginosa MDR isolates will further increase the resistance capacity of these isolates. Furthermore, our findings revealed the presence of int 1 and int 3 genes in the plasmid DNA from one particular strain of $P$. aeruginosa which, to the best of our knowledge, is uncommon. Considering the results from this study, it appears that a greater part of the antimicrobial agents employed are unsuitable for the treatment of the causative agents isolated from the surgical wounds which may be due to the presence of integrons in their plasmids. Of all the antibiotics used, Ciprofloxacin recorded the highest sensitivity and may possibly be the drug of choice.

\section{Conclusion}

The presence of Int1 and Int3 integron genes in the plasmid DNA of the multidrug resistant $P$. aeruginosa bacteria isolates is of serious healthcare concern , as they can be transferred to other non- MDR bacteria. We found a high antibiotics resistance among the $P$. aeruginosa isolated from the surgical wounds in our study. The results will assist to develop control strategies for the bacterial infections. The presence of integron genes in the plasmid DNA of the bacteria can assist in making most of the plasmid- positive isolates become MDR. Thus, efforts to maintain the correct use of antibiotics are supreme in order to avoid therapeutic failure, and is indispensable for choosing the appropriate therapy, routine antibiotic surveillance programs, and management of surgical wound infection control practices. However, more studies need to be carried out to examine the gene cassettes present in the plasmid DNA of somMDR and prevalence of class 1,2 and 3 integrons in other bacteria plasmid in recent years. The result will assist to develop control strategies for bacterial infections.

\section{Acknowledgements}

The authors wish to sincerely thank Dr. Mrs. Joy Ehiaghe, Mr. Roland Iyen and Mr. Prince Ikhuiwu of Lahor Research Laboratories and Diagnostics Centre, Benin City, Nigeria for their assistance throughout the study.

\section{References}

Alan V, Jesus M, Rober WJ. The Role of Plasmid in Phytopathogenic Bacteria: Mobile Arsenals, J. Gen. Virol., 2001; 147(4): $4763-4780$.

Breidenstein EB, de la Fuente-NuÂ ñez C, Hancock RE. Pseudomonas aeruginosa: all roads lead to resistance. Trends Microbiol., 2011; 19(8): $\quad 419 \quad-\quad 426$. 
https://doi.org/10.1016/j.tim.2011.04.005 PMID: 21664819

Cambray G, Guerout AM, Mazel D. Integrons. Annu. Rev. Genet., 2010; 44: 141 - 466. https://doi.org/10.1146/annurev-genet-102209163504 PMID: 20707672

Cheesbrough M. District Laboratory Practice Manual in Tropical Countries, part 2. New York, Cambridge University Press, 2000.

Church D, Elsayed S, Reid O, Winston B, Lindsay R. Burn wound infections. Clin. Microbiol. Rev., 2009; $19(2): 403 \quad-\quad 434$. https://doi.org/10.1128/CMR.19.2.403-434.2006 PMID: 16614255

Clinical and Laboratory Standards Institute. Performance standards for antimicrobial susceptibility testing 21st informational supplement, M100-S21. CLSI, Wayne, PA, 2011.

Clowers RC. Molecular Structure of Bacterial Plasmids," Bacteriological Reviews, 2004; 36(3) 1972, $361-405$.

Dellinger EP, Hausmann SM, Bratzler DW. Hospitals Collaborate to Decrease Surgical Site Infections. American Journal of Surgery. 2005; 190:9 - 15 .

Deng Y, Bao X, Ji L, Chen L, Liu J, Miao J. Resistance integrons: class 1, 2 and 3 integrons. Ann. Clin. Microbiol. Antimicrob., 2015; 14: 45. https://doi.org/10.1186/s12941-015-0100-6 PMID: 26487554

Domingues S, da Silva GJ, Nielsen KM. Integrons: vehicles and pathways for horizontal dissemination in bacteria. Mob. Genet. Elements., 2012; $2(5): \quad 21 \quad-\quad 223$. https://doi.org/10.4161/mge.22967 PMID:23550063

Ehiaghe J, Eghiaghe FA, Nwobu RAU, Nwiyi PO. Prevalence and multidrug antimicrobial susceptibility of bacteria isolates obtained from surgical site in Nigeria. Int. J. Curr. Microbiol.
App. Sci., 2016; 5(7): 708 - 715. http://dx.doi.org/10.20546/ijcmas.2016.507.081

Eremwanarue O. A. and Shittu, H. O. (2018). Antimicrobial activity of Moringa oleifera leaf extracts on multiple drug resistant bacterial isolates. Nigerian Journal of Biotechnology, 35(2): $16-26$.

Fair RJ, Tor Y. Antibiotics and bacterial resistance in the 21st century. Perspect. Medicin. Chem., 2014; $6: \quad 25 \quad$ - 64. https://doi.org/10.4137/PMC.S14459 PMID: 25232278

Fluit A, Schmitz FJ. Resistance integrons and super-integrons. Clin. Microbiol. Infect., 2004; 10(4): $272 \quad-\quad 288$. https://doi.org/10.1111/j.1198743X.2004.00858.x PMID: 15059115

Fontana R, Cornaglia G, Ligozzi M, Mazzariol A. The final goal: penicillin-binding proteins and the target of cephalosporins. Clinical. Microbiol. Infect., 2000; 6(3): $34-40$.

Gillings MR. Integrons: past, present, and future. Microbiol. Mol. Biol. Rev., 2014; 78(2): 257 - 277. https://doi.org/10.1128/MMBR.00056-13 PMID: 24847022

Gu B, Tong M, Zhao W, Liu G, Ning M, Pan S. Prevalence and characterization of class I integrons among Pseudomonas aeruginosa and Acinetobacter baumannii isolates from patients in Nanjing, China. J. Clin. Microbiol., 2007; 45(1): 241 - 243. https://doi.org/10.1128/JCM.0131806 PMID: 17122024

Moazami GS, Eftekhar F. Multidrug resistance and integron carriage in clinical isolates of Pseudomonas aeruginosa in Tehran, Iran. Turk. J. Med. Sci., 2015; 45: $789-793$.

Mohadeseh Z, Gilda E, Hengameh Z, Masoumeh K, Kazem B, Hanieh A, Seyed MM, Marzieh S. Prevalence of class 1, 2 and 3 integrons among multidrug-resistant Pseudomonas aeruginosa in Yazd, Iran. Iran. J. Microbiol., 2018; 300 - 306. 
Mohammadalipour Z, Kargar M, Doosi A. High Frequency of Class 2 and 3 Integrons Related to Drug Resistance in Clinical Isolates of Diarrheagenic E. coli in Iran. Novel Biomedical, 2017; 5(1): $30-36$.

Mohammed A, Adeshina GO, Ibrahim YKE. Retrospective incidence of wound infections and antibiotic sensitivity pattern: A study conducted at the Aminu Kano Teaching Hospital, Kano, Nigeria. International journal of medicine and medical sciences, 2013; (55):60 - 66.

Nikokar I, Tishayar A, Flakiyan Z, Alijani K, Rehana-Banisaeed $S$, Hossinpour M. Antibiotic resistance and frequency of class 1 integrons among Pseudomonas aeruginosa, isolated from burn patients in ilan, Iran. Iran. J. Microbiol., 2013; 5(1): 36 - 41. PMID: 23466812

Oni AA, Ewete A, Gbaja AT, Folade AF, Mutiu WB, Adeyemo DA, Bakare RA. Nosocomial Infection: Surgical Site Infection in UCH Ibadan, Nigeria. Nigeria Journal of Surgical Research. 2006; 8(12):19 - 23.

Rossolini G, Mantengoli E. Treatment and control of severe infections caused by multiresistant Pseudomonas aeruginosa. Clin. Microbiol. Infect., 2005; 11(4): $17-32$.

Shibata N, doi Y, Yamane K, Yagi T, Kurokawa H, Shibayama K, PCR typing of genetic determinants for metallo-beta-lactamases and integrases carried by gram-negative bacteria isolated in Japan, with focus on the class 3 integron. J. Clin. Microbiol., 2003; 41: 5407 - 5413.

Strateva T, Yordanov D. Pseudomonas aeruginosa $\pm a$ phenomenon of bacterial resistance. J. Med. Microbiol., 2009; 58(9): 1133 -1148. https://doi.org/10.1099/jmm.0.009142-0 PMID: 19528173

Sulochana D, Mamta D, Biswajeet S. Susceptibility Pattern of Aerobic Bacterial Isolates from Wound swab. Indian Medical Gazette, 2014; $355-359$.

Sun G, Yi M, Shao C, Ma J, Zhang Q, Shao S. Novel Class 1 Integrons in multi-drug resistant isolates from Eastern China. Indian. J. Microbiol., 2014; 54(2): $227 \quad-\quad 231$. https://doi.org/10.1007/s12088-013-0441- 9 PMID: 25320427

Sunde M. Prevalence and characterization of class 1 and class 2 integrons in Escherichia coli isolated from meat and meat products of Norwegian origin. Journal of Antimicrobial Chemotherapy, 2005; 56: 1019 - 1024.

WHO, Bulletin of the World Health Organization; 2011. 89:757 - 765 .

Xu Z, Li L, Shirtliff ME, Alam MJ, Yamasaki S, Shi L. Occurrence and characteristics of Class 1 and 2 integrons in Pseudomonas aeruginosa isolates from patients in southern China. J. Clin. Microbiol., 2009; 47(1): 230 - 234. doi: $\underline{10.1128 / J C M .02027-08}$

Yah SC, Eghafona NO, Oranusi S, Abouo AM. Widespread plasmid resistance genes among Proteus species in diabetic wounds of patients in the Ahmadu Bello University Teaching Hospital (ABUTH) Zaria. African J. Biotechnol., 2010; 6: 1757 - 1762. DOI: $10.5897 / A J B 2007.000-2258$ 